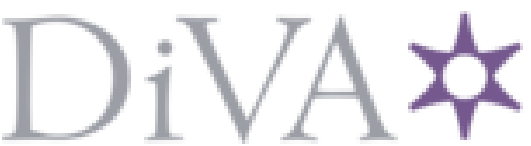

http://www.diva-portal.org

\title{
Postprint
}

This is the accepted version of a paper published in Utilitas. This paper has been peerreviewed but does not include the final publisher proof-corrections or journal pagination.

Citation for the original published paper (version of record):

Risberg, O. (2016)

Weighting Surprise Parties: Some Problems For Schroeder.

Utilitas, 28(1): 101-107

https://doi.org/10.1017/So953820815000394

Access to the published version may require subscription.

N.B. When citing this work, cite the original published paper.

Permanent link to this version:

http://urn.kb.se/resolve?urn=urn:nbn:se:uu:diva-262064 
[Pre-print. Please cite the (2016) version in Utilitas 28 (1), 101-7,

doi:10.1017/So953820815000394]

Weighting Surprise Parties: Some Problems for Schroeder

OLLE RISBERG

Uppsala University

\begin{abstract}
In this article I argue against Schroeder's account of the weight of normative reasons. It is shown that in certain cases, an agent may have reasons she cannot know about without them ceasing to be reasons, and also reasons she cannot know about at all. Both possibilities are troubling for Schroeder's view.
\end{abstract}

\title{
I. INTRODUCTION
}

In the excellent Slaves of the Passions, Mark Schroeder argues against his rivals with a case based on a surprise party. ${ }^{1}$ However, I worry that Schroeder's own views are troubled by the very same case. The aim of the paper is to outline this worry.

I will focus on Schroeder's account of the weight of reasons. On his view, the weight of reasons is a normative matter: a reason $A$ is weightier than a reason $B$ if and only if it is correct to place more weight on $A$ in deliberation. ${ }^{2}$ From this, Schroeder infers that 'what an agent ought to do would also be the result of correct deliberation from full

1 Mark Schroeder, Slaves of the Passions (Oxford, 2007).

2 This is the claim Schroeder calls Still Attractive (Slaves, p. 140), and has elsewhere called a 'platitude' ('Weighting for a Plausible Humean Theory of Reasons', NOÛS 41 (2007), pp. 110-32, at footnote 20). Calling it is his 'account' of the weight of reasons is really a bit too quick, though, as it is derived from more basic principles. Note also that in Slaves, the principle is formulated in terms of sets of reasons, rather than reasons plain and simple. None of this makes any difference for our purposes. 
information'.3

This is a familiar idea. For one, Michael Smith holds that it is a platitude that an agent 'has a reason to act in a certain way just in case she would be motivated to act in that way if she were rational', where rationality includes full information. ${ }^{4}$ Bernard Williams accepts a similar view, roughly holding that I have reason to do what I would desire to do after correctly deliberating from true beliefs. 5 I focus on Schroeder in this paper, his position being the most developed, but it should be apparent how the problems generalize. After presenting Schroeder's view in section II, I go on to argue against it in sections III and IV. The paper then ends with a summary of the arguments in section V.

Before we begin, two clarifications are called for. Firstly, in my discussion of reasons, what I have in mind is normative reasons - facts that favour or disfavour certain actions rather than motivating or explanatory reasons. Secondly, for argument's sake, I assume that Schroeder's view about normative reasons is true. On this broadly Humean view, normative reasons to perform a given action are facts that partly explain why this action would promote the agent's desires. ${ }^{6}$

(Notably, promoting desires is to be distinguished from satisfying them. An action promotes my desire if and only if it the action makes it more likely that my I desire is satisfied, compared to if I do nothing.7)

3 Schroeder, Slaves, p. 131.

4 Michael Smith, The Moral Problem (Oxford, 1994), p. 62; see also Christine Koorsgard, 'Skepticism About Practical Reason', The Journal of Philosophy 83 (1986), pp. 5-25. Notably, while Smith's ultimate 1994 account avoids the problem I discuss, Schroeder explicitly distances himself from such 'counterfactual' theories of reasons (Slaves, ch. 1, esp. fn. 4). Moreover, as Smith uses the alleged platitude to support his account (The Moral Problem, pp. 150-1), its falsity would be problematic for him as well. Bernard Williams, 'Internal and External Reasons', Moral Luck, ed. B. Williams (Cambridge, 1981), pp. 101-13.

6 Schroeder, Slaves, p. 29.

7 Schroeder, Slaves, p. 113. 


\section{SCHROEDER'S ACCOUNT}

Schroeder discusses the weight of reasons in the seventh chapter of Slaves. The topic is familiar: there are often pro tanto reasons to perform acts we ultimately ought to refrain from. Suppose for example that I consider whether to have another ice-cream; while this would be quite enjoyable, it would be slightly bad for my teeth. In this case, one of the reasons may outweigh the other. Perhaps what I ought to do, all things considered, is to have the ice-cream. If so, the fact that it is bad for my teeth still disfavours my action of eating it; this reason just is not weighty enough to beat the reason that favours having the ice-cream.

To account for complexities like these, we need a theory of the weight of reasons. Schroeder sets out to give us just that - what we get is a rather intricate account, and I will set its details aside here. In general terms, on this view, the weight of reasons is explained in terms of correctness. ${ }^{8}$ Schroeder endorses:

Weight. A reason $A$ is weightier than a reason $B$ if and only if it is correct to place more weight on $A$ than on $B$ in deliberation. ${ }^{9}$

To illustrate how this principle works, let $A$ be the fact that eating the ice-cream would be enjoyable, and let $B$ be the fact that it would be bad for my teeth. If $A$ is weightier than $B$, Weight implies that in deliberating about what to do, it is correct for me to place more weight on the fact that eating the ice-cream would be enjoyable (i.e. the fact that favours having the ice-cream), and less weight on the fact that it is bad for my teeth.

8 Correctness, moreover, is explained in terms of yet more reasons - in this sense, Schroeder's view is recursive. See Schroeder, Slaves, ch. 7.3, especially p. 138.

9 Schroeder, Slaves, p. 140. 
From this principle and some plausible background assumptions (such that agents ought to do what there is most reason for them to do), Schroeder derives a prediction:

Prediction. An agent ought to perform some act if and only if this act would be the result of her correctly deliberating from full information. ${ }^{10}$

How can we derive Prediction from Weight? Schroeder reasons as follows. A fully informed agent is aware of all her reasons. Moreover, to deliberate correctly is (at least) to correctly place weight on one's reasons; i.e., to place most weight on the reasons it is correct to place most weight on, and so on. Further, as the fully informed agent is aware of all her reasons on both sides, she would properly place weight on all of them in correct deliberation.11

Thus, Weight seems to imply that what an agent ought to do would be the result of her correctly deliberating from full information. Schroeder thinks this is 'a very nice prediction', as it is 'puzzling to think that correct deliberation from complete information could lead us astray from what we ought to do'.12

In my view, Schroeder's account clearly has its merits. Above all, it promises to explain why some reasons are weightier than others, rather than leaving this an unexplained or primitive notion. But there are also problems. In particular, Prediction is not a nice prediction; it is rather a false prediction. And Weight is no better off. Furthermore, perhaps it is puzzling if correct deliberation from full information would result in actions

10 Schroeder, Slaves, p. 131.

11 It is not clear that the demand for full information actually does any work in the prediction. Since Schroeder's account of correct deliberation seems to require that we put weight even on reasons we are unaware of, then it appears that correct deliberation from incomplete information too always results in acts the agent ought to perform. But I will not press this issue further here.

12 Schroeder, Slaves, p. 132. 
we ought to refrain from, but we will soon see that this is quite beside the point.

I will argue in support of these claims by a case from earlier in Slaves. The case gives rise to two distinct problems for Schroeder's view. The first problem is that agents sometimes cannot know about their reasons without them ceasing to be reasons; the second is that agents sometimes cannot know about their reasons at all. Let me explain.

\section{A PROBLEMATIC REASON}

In chapter 2 of the book, Schroeder asks us to consider the case of Nate. Nate hates most parties, but not all of them - he thoroughly enjoys successful surprise parties held in his honour. So let us imagine that a surprise party is waiting for Nate at his home, and suppose also that he is unaware of it. Schroeder holds that 'given Nate's situation, the fact that there is a surprise party waiting for him now at home is a reason for him to go home'.13

The claim is plausible, but subtly ambiguous. On one reading, Nate's reason to go home is a fact he can know about; on the other, is is a fact he cannot know about. In what follows, we will see that Schroeder is committed to Nate having reasons of both these kinds. This gives rise to multiple problems.

To begin, suppose Nate's reason to go to the party is constituted by a fact that he can know about. This is not difficult: perhaps his reason to go home is the fact that a party, which is supposed to be a surprise party, is waiting for him there. This fact partly explains why Nate's going home would promote some desire of his (such as the desire to go to a successful surprise party), and thus, Schroeder too must accept that it favours Nate's going home. Moreover, the fact that a supposed surprise party is waiting is one that Nate could easily know about. Yet this is all we need to get Prediction in trouble.

Here is the problem. Nate's reason to go home is constituted by the fact that a supposed surprise party is waiting for him. However, if Nate had full information, he

13 Schroeder, Slaves, p. 33. 
would also know of this very fact: that a supposed surprise party awaits him. But this would ruin the surprise! And this, in turn, would ruin his reason to go home. Hence, if Nate would deliberate correctly from full information, the result would not be that he goes home; simply because if Nate had full information, he would not have a reason to go home. (Of course, it would still be true that a party awaits him, but this fact would no longer favour his action of going to it.)

It therefore follows from Prediction that in his present state of knowledge, it is not the case that Nate ought to go home. But this contradicts our earlier assessment of the situation. In his present state of knowledge, Nate has heard nothing about the party, and thus has a hefty reason to go home - even on Schroeder's own view.

Now, turn to Weight; Nate's reason casts doubt upon this principle as well. Since the fact that a party is waiting favours Nate's going home, Weight implies that it is correct for Nate to place weight on this reason in deliberation. (Insofar as Nate also ought to go home - which seems plausible - Weight implies that it is correct for him to place most weight on the reason in deliberation. ${ }^{14}$ ) And here we find another problem.

This problem springs from the fact that if an agent places weight on a given reason, it follows that she is aware of the reason. Thus, Nate cannot place weight on the fact that a party is waiting without knowing about it. But again, as soon as Nate learns that a party awaits him, this fact ceases to favour him going home - and in that case it would be incorrect for him to place weight on it. I conclude that while Nate has a reason to go home, it would not be correct for him to place weight on it in deliberation. This is a conclusion that directly contradicts Weight.

14 Whether or not Schroeder's view actually implies that Nate ought to go home depends on how we cash out 'the right kind of reasons' in deliberation (see Slaves, pp. 134-5). But be that as it may, I think this is what the view has to imply to be plausible. 


\section{ANOTHER PROBLEMATIC REASON}

We have seen that one of Nate's reasons to go home spells trouble for both Weight and Prediction. In this section, we look at another of his reasons to go home - a reason he cannot know about without violating the laws of logic. This gives rise to a different, and arguably more serious, problem for Schroeder.

Nate's second reason to go home is constituted by the fact that a real surprise party is waiting for him. By stipulation, let this be the conjunctive fact that there is a party waiting for Nate and Nate does not know about it. ${ }^{15}$ On Schroeder's view, this fact too is a reason for Nate to go home, as it partly explains why going home would promote Nate's desires. ${ }^{16}$ But it is a fact that Nate cannot under any circumstances know about, since him knowing the first conjunct is incompatible with truth of the second.

Unknowable reasons like this one present a new problem for Weight. (For Prediction, something like the problem from section III rather arises again.) Earlier, I complained that contra Weight, it would be incorrect for Nate to place weight on his reason - simply because if Nate was in the position to do this, the reason would have ceased to be a reason. This is not my present concern.

Instead, this is the problem I now wish to press: if Nate cannot know that a real surprise party is waiting, he cannot place weight on this reason in deliberation. And in that case, is it not preposterous to demand that he nevertheless ought to place weight on this

15 I thank Erik Carlson for stressing the significance of conjunctive facts like this. For what it is worth, this seems to be the reason Schroeder had in mind in the original case, as he claims that Nate has a reason he cannot know about (Slaves, p. 33). But one could also take him to mean that Nate could not know about his reason without it ceasing to be a reason, which rather suggests the reason discussed in section III.

16 Maybe you worry that this is somehow an illegitimate double-counting: surely Nate does not have two reasons to go home? In that case, note that this is one of the worries that Weight is designed to handle (see Slaves, p. 34 and ch. 7). 
reason (or, equally, to claim that this is the only correct way of deliberating)? So it would seem. Yet if Weight is true, then however Nate deliberates, he does it incorrectly - simply because correct deliberation requires him to place weight on a reason he cannot place weight on.

This implication is harsh. It would be difficult enough to accept that there are any situations at all where we cannot do what we ought to do - a fortiori, it is an astonishment if this turns out to be one of them.

\section{SUMMARY \& ENDING}

Now, let us take stock. In section III, we looked at one of Nate's reasons to go home: the fact that a supposed surprise party is waiting for him. Here, we saw that although this fact favours Nate's going home, it would not do so if he was fully informed. Hence, Prediction falsely implied that in his present state of knowledge, it is not the case that Nate ought to go home.

Further, we saw that if Weight is true, then it is correct for Nate to place weight on the fact that a party is waiting in deliberation. This implication too is implausible since Nate cannot place weight on this reason without knowing about it; and as soon as he learns of the fact that a party is waiting, this fact ceases to be a reason to go home.

Then, in section IV, we shifted the focus to another of Nate's reasons to go home: the fact that a real surprise party is waiting for him. We saw that while this fact too favours Nate's going home, it is a fact that Nate cannot know about. Hence, Weight demands that Nate does something he cannot do, which is an unreasonable demand.

Lastly, let me comment on Schroeder's support for Prediction: that it is 'puzzling to think that correct deliberation from complete information could lead us astray from what 
we ought to do'.17 We see now why this is beside the point. It is not as though Nate, if he would deliberate correctly from full information, would come to a false conclusion about how he ought to act. On the contrary, it may well be true that if Nate knew about the party, then he ought not to go home - because what Nate ought to do changes as he learns about his reasons. Schroeder's comment therefore fails to support Prediction; perhaps correct deliberation from complete information always results in acts we ought to do, but this is simply a different issue.

With that, the paper has reached its end. If the arguments here are on the right track, it is bad news. Schroeder's theory of the weight of reasons is important for many of his other projects - in particular for the daunting task of making moral reasons come out weightier than prudential ones, even though his view on normative reasons is desire-based. Thus, the problems we have discussed not only beset Weight and Prediction, but Schroeder's whole program..$^{18}$

olle.risberg@filosofi.uu.se

Schroeder, Slaves, p. 132.

18 I am thankful to Erik Carlson, Mark Schroeder and an anonymous reviewer for valuable comments on this paper. 